\title{
Aproximación evolutiva a la complejidad y al orden social temprano a través del estudio de representaciones rupestres de la quebrada de Matancillas (Puna argentina)
}

HeRnÁn J. MusCIO ${ }^{1}$

\section{RESUMEN}

A partir del estudio de la elaboración rupestre de la quebrada de Matancillas (Provincia de Salta, Puna argentina), discutimos desde la perspectiva evolucionista algunos aspectos de la conducta social durante el Período Temprano en la región (1000 AC - 400 DC). En la escala local esta evidencia indica una sociedad heterogénea, con una diversidad amplia de nichos sociales y un orden social androcéntrico. En la mesoescala, los geoglifos y petroglifos señalando rutas de movilidad y territorios, sugieren organizaciones sociales basadas en el intercambio entre grupos. Más particularmente, se sostiene que esta elaboración cultural sirvió para la reproducción de instituciones sociales derivadas de la competencia por el acceso y el uso del espacio productivo, donde intervino la transmisión cultural para la replicación de los diseños rupestres y de la información atinente a la conducta social.

Palabras claves: complejidad social - arte rupestre - economías de producción de alimentos - arqueología evolutiva - elaboración cultural y sociobiología.

\begin{abstract}
Based on the study of rock art in the gorge of Matancillas (Salta Province, Argentine Puna), this paper discusses, from an evolutionist perspective, a few aspects of social behavior during the Early Period in the region (1000 BC $-400 \mathrm{AD})$. In the local scale of analysis, it is argued that evidence suggests a heterogeneous society, with a wide diversity of social niches and an androcentric social order. In the meso-scale, the presence of geoglyphs and petroglyphs indicating routes of mobility and territories, suggests social organizations based on inter-group exchange. More particularly, we hold that this sort of cultural elaboration contributed to the reproduction of social institutions that derived from the competition over the access and use of productive spaces, where cultural transmission controlled the replication of rock-art designs and information regarding social behavior.
\end{abstract}

Key words: social complexity - rock art-food production economies - evolutionary archaeology - cultural elaboration and sociobiology.

Recibido: agosto 2005. Aceptado: diciembre 2005.

1 Grupo de Investigación Cultura, Comportamiento y Evolución (GICCE), Sección Arqueología, Universidad de Buenos Aires, 25 de mayo 217, $3^{\text {er }}$ piso (1002), Buenos Aires, ARGENTINA. Email: hmuscio@ciudad.com.ar

\section{Introducción}

La aplicación de modelos seleccionistas al análisis de sociedades humanas, posible luego de la formalización del modelo de fitness inclusivo (Hamilton 1964) de la teoría evolutiva de juegos (Maynard Smith 1964 y 1974; Trivers 1971; Dawkins 1976 y 1982; Gintis 2000), y la genética de la conducta (Tooby y Cosmides 1992) demuestran la existencia de una gran diversidad de adaptaciones sociales y sistemas organizativos, explicables por el principio de selección natural. Un aspecto crucial es que los procesos de evolución y dinámica de la conducta social no tienen patrones direccionales inherentes, sino contingentes con las propiedades del entorno (Krebs y Davis 1991). Esto descubre lo inadecuado de las nociones progresivistas de la evolución social (Dennet 1995; Dickens 2000). Dentro del marco seleccionista pueden analizarse, en escalas de tiempo arqueológico, tanto el surgimiento de instituciones sociales diferentes como las distintas trayectorias de aumento o disminución de la heterogeneidad de las sociedades humanas. El materialismo darwiniano permite distinguir los factores causales de estos procesos evolutivos.

Este trabajo aborda el estudio de las representaciones rupestres desde una perspectiva darwiniana, buscando establecer correlatos de esta producción cultural con la sociabilidad de poblaciones arqueológicas. Por esta razón su contenido teórico es inevitable. Tomando como caso de estudio las representaciones rupestres de Matancillas, Puna de la Provincia de Salta (Argentina), se discuten aspectos del orden social durante el Período Temprano. A partir de la consideración de las representaciones rupestres como elaboración cultural de alto contenido comunicacional (Muscio 2002), se abordan los aspectos funcionales de esta producción cultural, enfatizando el análisis de patrones en las representaciones relacionados con la dimensión espacial del comportamiento social y la interacción entre individuos y grupos. 


\section{Aspectos teóricos: Arqueología evolutiva y dinámica social}

La evolución de la sociabilidad humana, particularmente la interacción en grupos de acción colectiva, puede explicarse a partir de contextos selectivos favorables para el aumento del tamaño de los grupos sociales de primates (Dumbar 1999). Es decir, mediante un proceso selectivo favorable para la formación de unidades sociales grandes. En esta hipótesis, la competencia es la presión de selección natural (Foley 1995). Siguiendo este razonamiento, Kosse (1994) argumenta que la complejidad sirve para mantener la eficiencia funcional de los grupos sociales humanos, en relación al incremento de las interacciones y de la información, derivadas de un mayor número de individuos. Desde esta perspectiva, que considera a la competencia como la principal fuerza selectiva operando en los procesos de evolución social, construyo la argumentación subsiguiente.

El término complejidad refiere al aumento de la diferenciación de partes de un sistema cualquiera (Tainter 1995). En las poblaciones humanas la complejidad social se expande conforme aumenta la diversidad de sus nichos sociales y se modifican las relaciones organizacionales de la estructura social: los sistemas normativos que legitiman tales nichos. Ambos aspectos, organización y diversidad de nichos sociales, definen la escala de complejidad social. Los sistemas normativos son leyes societales, que controlan los conflictos de interés por el acceso a los recursos bajo competencia (Chagnon 2000: 119).

En la acepción más general, el concepto de nicho constituye el conjunto de las adaptaciones de los organismos a las variadas dimensiones de su entorno (Pianka 1995). Considerando la dimensión social del entorno, los nichos sociales pueden definirse como los roles sociales, que tienen los individuos en una organización social de cualquier escala (ver Sugiyama y Chacon 2000). El dominio del nicho social incluye al conjunto de adaptaciones individuales relacionadas con las propiedades de las organizaciones sociales de la población. Estas se relacionan estrechamente con la base económica (Winterhalder 2001). A partir de estas definiciones, la diversidad social (la cantidad total de nichos sociales distintos) y el sistema de relaciones organizacionales de la estructura social son propiedades de una población evolutiva.
Los nichos sociales ocupados por los individuos varían en relación al contexto socioecológico, las habilidades, el sexo y la historia de vida. En otras sociedades de primates existe una variedad de nichos sociales que incluyen jerarquías (Wilson 1975). Un mismo individuo puede simultáneamente ocupar más de un nicho social. Por ejemplo, en sociedades humanas, ser artesano especializado y cazador. El repertorio de comportamientos asociados a un nicho social puede resultar de la expresión de información genética, cultural o de ambas (Durham 1992). Cuando predomina la transmisión cultural para estos roles y cuando estos aumentan en diversidad, la información cultural atinente a la conducta social aumenta en el nivel del grupo.

La perspectiva evolucionista implica una ruptura con el pensamiento esencialista. Así, la complejidad social humana es conceptualmente una variable con una gradiente de estados, no reducibles a organizaciones típicas (bandas, jefaturas, señoríos, Estados). Además, el darwinismo difiere del paradigma progresivista spenceriano, ya que sostiene que la dinámica del comportamiento social está canalizada por las propiedades cognitivas de la especie y es sensible a las características cambiantes de la historia cultural y el entorno ecológico, y sin direccionalidad. En suma, se sostiene que la escala de complejidad de una sociedad humana es una función creciente de la competencia y de la proliferación de nichos sociales diferenciados (Muscio 2004).

En el marco teórico de la arqueología evolutiva, las representaciones rupestres son extensiones del fenotipo humano, cuya variación y persistencia pueden ser explicadas por procesos selectivos en distintos niveles, y por la acción de la transmisión cultural (O’Brien y Lyman 2002). El interés de este trabajo es explorar cómo esta construcción cultural es informativa de la sociabilidad de poblaciones con nichos económicos agropastoriles tempranos en la Puna de Salta.

\section{La ocupación de la quebrada de Matancillas: Agricultura, competencia y sociabilidad}

La quebrada de Matancillas se localiza sobre la Cordillera Oriental en el valle de San Antonio de los Cobres, con una altitud promedio de 3670 m.snm (Figura 1). Esta quebrada constituyó un hábitat local en el mosaico ecológico regional, 


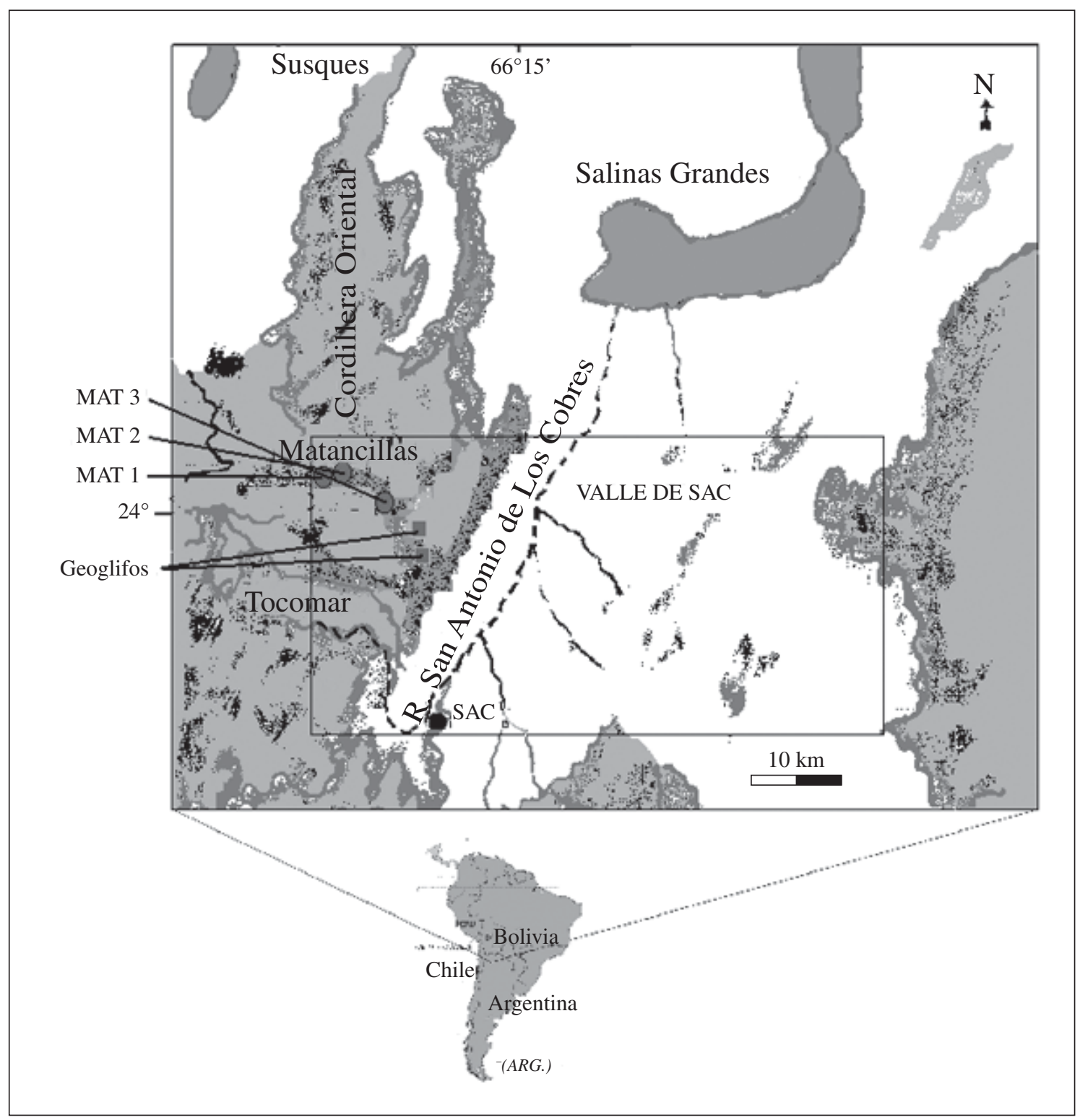

Figura 1. Localización de la quebrada de Matancillas y de los sitios arqueológicos mencionados en el texto.

favorable para su colonización por poblaciones con un nicho económico en el cual la agricultura fue la estrategia predominante (Muscio 2002). La información obtenida de los sitios Matancillas-1 y Matancillas-2 (en adelante M1 y M2 ) expone un tiempo de ocupación breve en la escala arqueológica. El rango radiocarbónico de la misma, obtenido a partir de cinco dataciones $\mathrm{C}^{14}$, está entre los 2040 440 AP (UGA 8624) y 1925 \pm 80 AP (AC 1659 ), fechas sin calibrar. Esto sugiere un proceso de colonización y extinción local oportunista, esperable en ambientes fluctuantes, donde la estocasticidad ambiental (fluctuaciones impredecibles) genera un entorno selectivo de riesgo. En este planteamiento, extinción local refiere a la extirpación de una población local de su hábitat. Los trabajos en Matancillas expusieron una distribución heterogénea de estructuras de cultivo, sugiriendo una táctica agrícola de manejo de riesgos, y exponiendo que la estocasticidad, propia del bioma de desierto de altura puneño, fue quizás la principal presión selectiva (Muscio 1998). 
La evidencia cerámica relaciona a la ocupación de Matancillas con la Tradición Alfarera San Francisco (TASF) (Muscio 2004). La estrategia tecnológica de esta ocupación estuvo orientada a la maximización de la utilidad de los recursos y fue altamente dependiente de materias primas no locales. Por ejemplo, las obsidianas de Zapaleri y Tocomar explican el $76 \%$ de los artefactos líticos. Esto permite sostener la existencia de interacciones sociales de gran escala espacial, entre poblaciones locales distantes. Tomando como centro a Matancillas, esta evidencia implica un espacio de interacción social de aproximadamente $96200 \mathrm{~km}^{2}$. Además, esta materia prima, domina la muestra de artefactos líticos de la quebrada de Urcuro, también en el valle de San Antonio de los Cobres. Su ocupación actualmente conocida es alrededor de 450 años posterior a la de Matancillas (Muscio 2004). Esto indica que las poblaciones locales de Matancillas y Urcuro participaron de una sociedad de macroescala, en donde las interacciones basadas en el flujo de bienes fueron perdurables en el tiempo. Por otra parte, la obsidiana de Cerro Zapaleri está presente también en Huirumpure (Susques) y en Las Cuevas (prepuna de la Provincia de Salta) (Yacobaccio et al. 2002). Cada uno de estos casos sugiere una profundidad temporal extensa de las redes de circulación de estos bienes, y la continuidad de largo plazo de una sociedad espacialmente muy inclusiva, que perduró aun cuando algunas de las poblaciones locales se extinguían. Sobre la base de esta información desarrollamos las principales hipótesis acerca del orden social que debió prevalecer durante el Período Temprano en la región. Nos interesa generar proposiciones en la escala local (la quebrada de Matancillas y sus inmediaciones) y en la mesoescala (la Subárea Circumpuneña), considerando los efectos de la competencia en la sociabilidad humana, para luego evaluar las representaciones rupestres bajo las mismas.

\section{Hipótesis de escala local}

En la escala local, la quebrada de Matancillas, una cuestión importante es el efecto de la escasez de los terrenos de cultivo. Podemos modelar esto apelando a funciones de fitness simples, pero que captan la naturaleza del problema (Smith y Winterhalder 1992). Así, planteamos que el valor del espacio productivo debió seguir una función creciente en los inicios de la colonización de
Matancillas durante el Período Temprano (Figura 2). Considerando el valor del espacio productivo en fitness esperamos que en un ciclo inicial $(t)$ este aumente aceleradamente en relación con su cantidad. Es decir, cada fracción x de terreno nuevo tiene un mayor valor marginal al ya poseído. En la Figura 2 el paso de $\mathrm{x}_{1}$ a $\mathrm{x}_{2}$, sobre el eje $y$ ilustra este razonamiento. En este caso la nueva unidad de espacio a incorporar, de idéntica cantidad, triplica la ganancia de fitness $\left(w_{2}=3 w_{1}\right)$. Así, existe intergrupalmente un incentivo creciente por la demanda del espacio local.

En nuestro planteamiento la demanda de espacios de cultivos debió seguir dos objetivos: 1) la obtención de parcelas para satisfacer los requerimientos de las unidades domésticas, y 2) la dispersión espacial para minimizar riesgos. Así, la escasez del espacio productivo plantea un escenario de aumento de la competencia, conforme aumentan los requerimientos productivos de manera densodependiente. Esto hace esperable la emergencia de comportamientos basados en la competencia y la posible exclusión territorial que demandan sistemas de ordenamiento de las posibilidades de dispersión espacial y acceso al espacio (Wilson 1975; Winterhalder y Goland 1997). Ambos aspectos debieron requerir de órdenes sociales e instituciones adecuadas para garantizar el acceso local a los campos de cultivos, mitigando la competencia interindividual a partir de la existencia de jerarquías que absorben los costos de mantener el bien colectivo: el orden social, obteniendo beneficios privados (Boone 1992). Estos

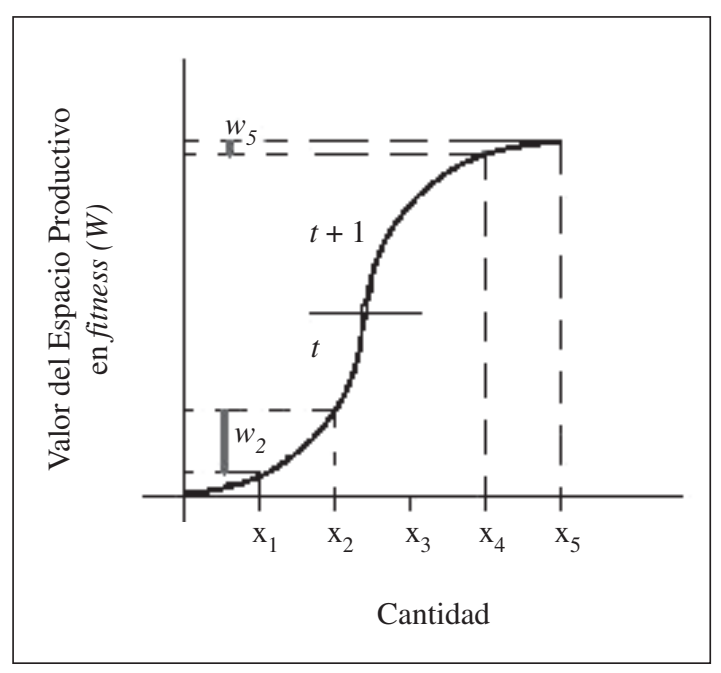

Figura 2. Función de fitness del espacio productivo. 
beneficios pueden ser ganancias en fitness individual reproductivo o en fitness inclusivo sin necesidad de acceso diferencial a recursos económicos, sino ligados al estatus (Durham 1992; Chagnon 2000). La existencia de una sociedad heterogénea, con líderes, es una de las hipótesis que discutiremos.

\section{Hipótesis de mesoescala}

Es importante considerar que los beneficios de la explotación de recursos limitados no pueden crecer indefinidamente de manera exponencial. Por esto esperamos que, conforme aumente la persistencia de la población local en un estado de crecimiento no estacionario, la función de valor del espacio productivo pronto revierta a un ciclo de beneficios marginales decrecientes. En la Figura 2 esto ocurre en $t+1$. Aquí el beneficio obtenido $\left(w_{5}\right)$, en el pasaje desde $\mathrm{x}_{4}$ a $\mathrm{x}_{5}$, es mínimo comparado a $\left(w_{2}\right)$ del ciclo anterior. En tal contexto, la competencia intragrupal por el espacio declina, y puede ser mucho más costosa que la obtención de recursos críticos a partir de poblaciones vecinas, lo que da lugar a la emergencia de sistemas de cooperación basados en el intercambio recíproco, en economías abiertas y simbióticas. Esto es de especial importancia en relación con las tácticas de manejo del riesgo, que consumen espacio extra y aumentan los costos globales de la producción. En este contexto se espera que decline el incentivo por la búsqueda de mayor espacio si existe la posibilidad de obtener recursos que amortigüen el riesgo de vecinos. Se trata de un cambio en la táctica de manejo de riesgo, que aumenta la escala espacial de la obtención de recursos a partir del intercambio interregional en detrimento de la búsqueda de más espacio local para la dispersión de campos (Muscio 2004).

Considerando que los hábitats locales de la Puna norte de Argentina para poblaciones agroganaderas son, en general, de baja calidad, esperamos que el ciclo de valor decreciente del espacio productivo se alcance rápidamente con densidades poblacionales bajas. En este contexto predominarán estrategias de beneficio mutuo entre poblaciones vecinas en la mesoescala, la Subárea Circumpuneña. Esto da lugar a la emergencia y persistencia selectiva de redes de interacción basadas en el intercambio interregional, donde las unidades domésticas son las unidades de intercambio; pero también a la competencia intergrupal por los espacios locales, y la defensa y demarcación territorial de estos. Esta hipótesis de cooperación y competencia intergrupal en la mesoescala es el segundo planteamiento que abordaremos en el estudio de las representaciones rupestres de Matancillas. Particularmente, analizando la producción rupestre vinculada con la movilidad interregional y la demarcación de territorios, en la línea desarrollada por otros autores (Núñez 1976, 1983; Yacobaccio 1979; Muñoz y Briones 1998; Aschero 2000).

Más generalmente, Aschero (2000: 17) destacó el rol de las representaciones rupestres como parte de estrategias de "comunicación visual" de las sociedades surandinas, cuya modalidad habría cambiado formas y significados a lo largo del tiempo. Para el Período Temprano propuso un modelo de dos bloques temporales, con diferentes patrones en la diversidad de las representaciones rupestres circumpuneñas. El primero "a" ( $c a$. 2500 AC a 900 DC) se caracterizó por una alta diversidad regional de diseños, y estuvo asociado con redes de tráfico caravanero de larga distancia y con los inicios de las economías productivas (Aschero 1996). El segundo "b" (ca. 900-1000 DC) se caracterizó por una mayor homogeneidad de los patrones de diseño, principalmente de figuras humanas y camélidos, lo cual se vinculó con la reducción de las distancias abarcadas por las redes de tráfico y por un patrón de cambio mucho más rápido. Exploraremos también estas ideas en el estudio de las representaciones rupestres de Matancillas, en relación con los mecanismos de transmisión cultural que pueden explicar este patrón. Aschero concibe explícitamente a las representaciones rupestres como elementos sujetos a la transmisión de información socialmente aprendida, replicados selectivamente por los individuos en contextos socioeconómicos particulares (Aschero 1996 y 2000). Por lo tanto, esta propuesta es adecuada para estudiar la variabilidad en los diseños de elementos iconográficos, a partir de su replicación diferencial mediada por la transmisión cultural, es decir, en términos darwinianos (Boyd y Richerson 1985). Más aún, este acercamiento es compatible con la concepción de las representaciones rupestres como una extensión del fenotipo humano. 


\section{Características de la elaboración rupestre de Matancillas}

La elaboración rupestre de Matancillas consiste en petroglifos y geoglifos. Los primeros son grabados sobre soportes de ignimbrita que afloran en las serranías contiguas a los sitios excavados M1, M2, y de un sitio no excavado, Matancillas-3 (M3). También se presentan no asociados a sitios con evidencias de ocupaciones, estos son Matancillas Petroglifos-1 y 2 (MP1 y MP2). Los geoglifos son grandes camélidos hechos con bloques de cuarzo blanco alineados, sobre sectores altos del faldeo de los cerros. Detectamos dos conjuntos, Matancillas Geoglifos-1 y 2 (MG1 y MG2). Los geoglifos y los petroglifos se diferencian por los motivos representados, los recursos visuales empleados y el emplazamiento de las representaciones.

La evidencia de geoglifos es nueva en Argentina. No así en el norte de Chile (Núñez 1976 y 1983). Sin embargo, entre ambas existen diferencias sustanciales de diversidad, estilo, diseño, y manufactura. En Matancillas son estructuras simples y esquemáticas. Discutiremos esta evidencia sobre la base de la temporalidad de los sitios excavados. Desde el diseño, podría sugerirse una temporalidad algo mas tardía en el Formativo regional, sobre la base de la tendencia al esquematismo y la linealidad detectada en el arte rupestre para la Puna argentina (Aschero 1996). Sin embargo, la representación de camélidos en geoglifos asociados a rutas tiene antecedentes en el Formativo del norte de Chile, particularmente en Cerro Sombrero, que si bien se diferencian de los de Matancillas por la modalidad de ejecución son similares en su diseño (Muñoz y Briones 1998). Dado que en Matancillas no hay evidencias de ocupaciones posteriores al $100 \mathrm{DC}$, asignamos hipotéticamente los geoglifos al Período Temprano (González 1977). Junto a los geoglifos, en superficie se hallaron cabezales líticos triangulares, similares a los de excavación, dando más sustento a la asignación temporal (Muscio 2004). Otros indicadores cronológicos más robustos resolverán esta hipótesis.

En cuanto a lo metodológico, realizamos el relevamiento de las representaciones rupestres mediante la confección de calcos sobre acetato, el procesamiento de fotografías mediante filtros digitales de contraste, registro fílmico y localización geográfica GPS de los lugares con represen- taciones rupestres. La metodología se basó en considerar a las representaciones individuales como unidades mínimas de análisis. Estas, al igual que los artefactos, poseen atributos que caracterizan a su diseño y a su variabilidad. Las representaciones individuales o los agregados de representaciones, fueron catalogados asignándoseles un número de panel. Los paneles consisten en sectores discontinuos de los afloramientos rocosos del soporte de los petroglifos. La discontinuidad de los mismos es consecuencia de la forma discreta de la distribución de planos naturales en los afloramientos rocosos, útiles como soporte. A continuación caracterizamos a los petroglifos y a los geoglifos de Matancillas.

\section{Petroglifos}

Los petroglifos fueron realizados mediante el picado de cuerpo lleno. En las representaciones humanas tienen una fuerte captación analítica (Figura 3). Los diversos motivos incluyen figuras humanas simples, figuras humanas zoomorfizadas, figuras zoomorfas, pisadas humanas y de camélidos, líneas sinuosas, y representaciones esquemáticas de los asentamientos, o maquetas. Estas son circunferencias y figuras geométricas irregulares de distinto tamaño, adosadas. En un caso inferimos que junto al asentamiento se representó el curso del río Matancillas, con líneas sinuosas coincidentes con el recorrido del cauce en el sector de emplazamiento del panel. En términos generales, la mayor parte de estas representaciones se hallan aisladas en los paneles. En algunos casos, donde se presentan agrupaciones, se pueden distinguir "escenas", entendiendo a estas últimas como a los agregados de representaciones rupestres que constituyen una unidad de representación de acciones, llevadas a cabo por entidades humanas, no humanas o sobrenaturales, y donde fundamentalmente intervienen las interrelaciones entre los referentes representados y las articulaciones con el soporte sobre el que están dispuestas. En estos términos, las escenas pueden representar acciones de la vida cotidiana, ritual o religiosa (Figura $3 e)$. De la misma manera que las representaciones individuales, las escenas sirven para la transmisión de información social formando parte de la "cultura simbólica" (sensu Chase 1999).

En M1 y M2 la localización de los paneles rupestres está en vinculación directa con los sitios. En ambos casos se ubican en los farallones de 


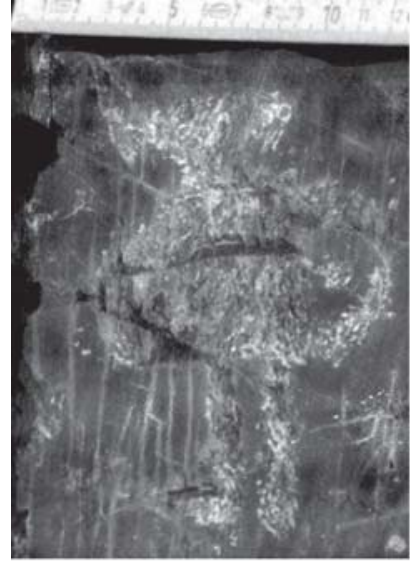

a

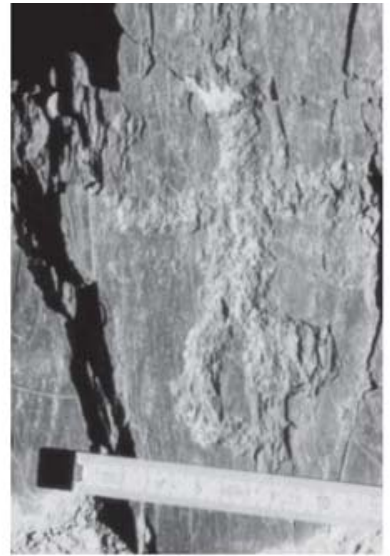

b

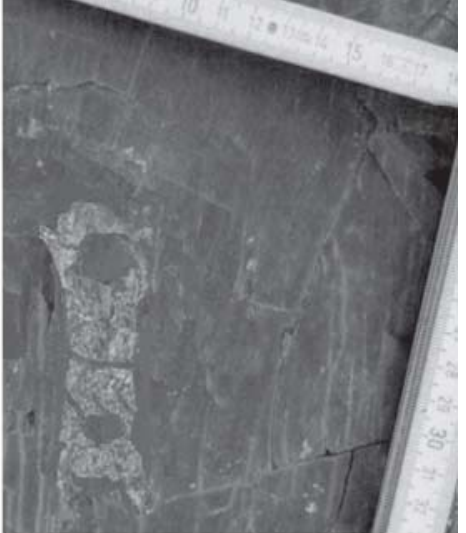

$\mathrm{C}$

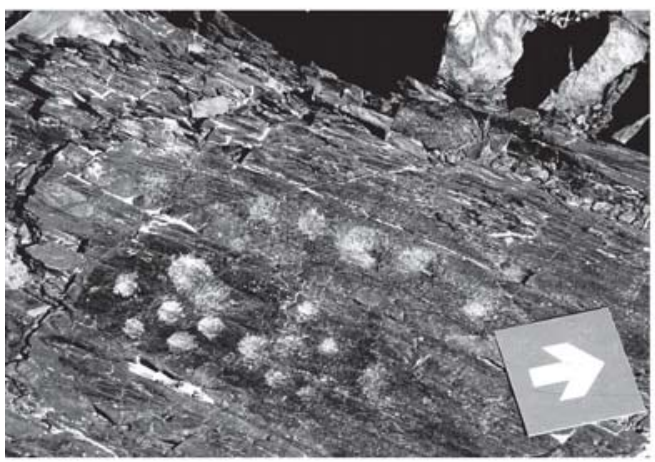

d

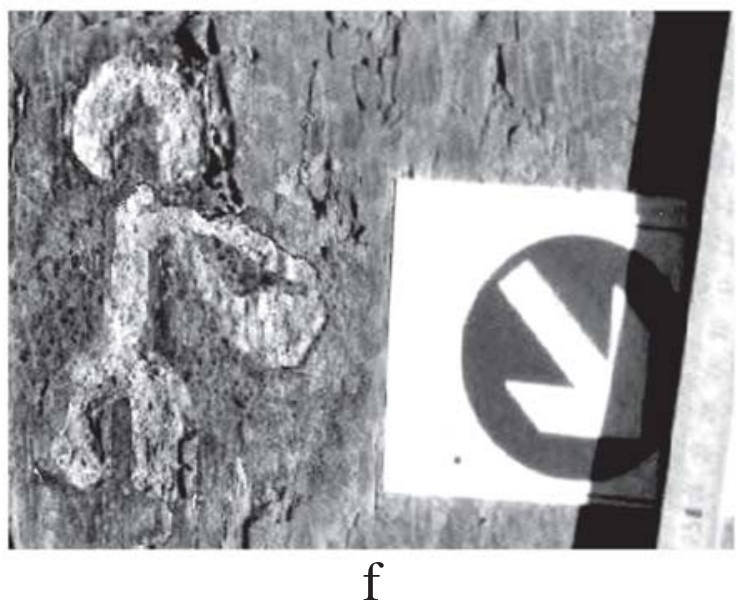

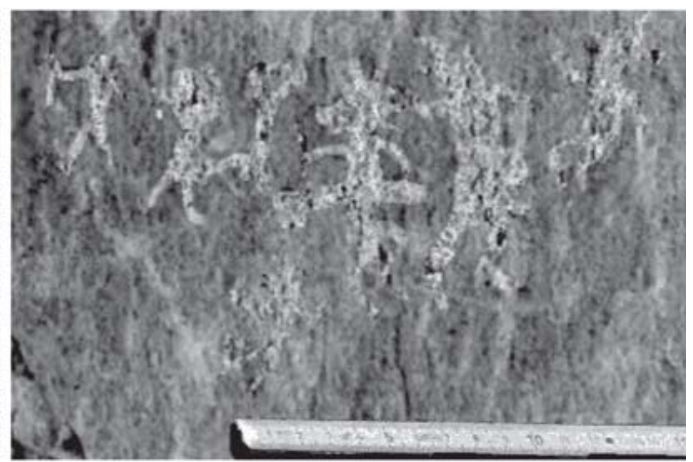

e

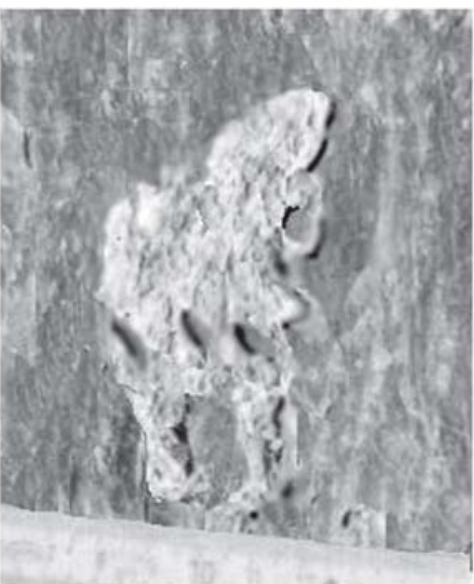

g

Figura 3. Ejemplos de representaciones rupestres de Matancillas: a, b, c, f y g) representaciones antropomorfas; d) pisadas; e) escenas. 
ignimbrita que afloran en los cerros. En M1 los paneles con petroglifos se hallan en todo el sector oriental del sitio. El total de paneles relevados fue de 14. En M2 el total de petroglifos es de tres, localizados en el sector occidental del sitio, separados del mismo por un pequeño cauce. En M3, que está emplazado en el sector intermedio de la quebrada, el total de paneles es de 72. Las representaciones rupestres se concentran en un peñasco de ignimbritas que sirvió para el soporte de múltiples paneles. Este sitio aún no se ha excavado. No obstante, en todo el sector donde se localizan los paneles existen concentraciones de artefactos de superficie comparables a las de M1 y M2, canchones de cultivo probablemente arqueológicos y corrales arqueológicos. Esto sugiere que el contexto en el cual se replicaron las representaciones rupestres fue doméstico y productivo.

Los petroglifos de MP1 y MP2 se localizan en contextos totalmente diferentes al resto. El emplazamiento de ambos ocurre en sendas que conectan a la quebrada de Matancillas con el fondo de cuenca del valle de San Antonio de los Cobres, sin estar asociados a ninguna clase de instalación residencial o productiva. Esto no podría ser de otra manera, dado que los petroglifos se emplazan en sendas escarpadas entre los cerros de gran pendiente y altura. En MP1 hay un solo panel que se encuentra destruido por la exfoliación del soporte. Por esta razón no se discutirá este conjunto, pero señalamos que los apenas cinco motivos que se conservan, constituyen pisadas humanas y círculos picados. En MP2, hay dos paneles bien conservados. Estos se emplazan lateralmente a una senda muy estrecha y de gran pendiente, localizada en un sector muy escarpado del tramo intermedio del cerro meridional en el cual comienza la quebrada de Matancillas. Ambos conjuntos de representaciones están distanciados de los sitios residenciales aproximadamente $8 \mathrm{~km}$. Por la ubicación de los mismos, el contexto de uso y replicación de las representaciones rupestres fue de tránsito y movilidad.

Todos los petroglifos se disponen de manera horizontal o ligeramente inclinados con respecto al terreno. Por esto, el espacio visual en su conjunto es perceptible ubicándose por encima de las figuras, es decir, cuando el observador se posiciona verticalmente a las mismas. No creemos que esto se deba a los condicionantes de la roca de base sobre la producción rupestre, debido a que esta ofrece superficies sobre las cuales se pudieron haber realizado grabados dispuestos en planos laterales, para ser observados de manera perpendicular, como ocurriría en el caso de paredes naturales. En consecuencia, consideramos que se trató de un atributo visual que formó parte del diseño de los petroglifos, cuya ejecución fue realizada para que sean vistos en situaciones tales como las de caminata. Es muy significativo el caso de M1 y M3, donde las representaciones son visibles conforme se asciende o desciende del sitio; y de las presentaciones de MP1 y MP2, donde son visibles cuando se transitan las sendas de ascenso y descenso entre los cerros.

\section{Geoglifos}

Los geoglifos fueron construidos mediante hileras de bloques de cuarzo de dimensiones variadas, enterrados en los sectores altos, pero menos escarpados de los cerros (Figura 4). Las representaciones consisten en grandes figuras de crías de camélidos y camélidos adultos (Figura 4a). El diseño de estas figuras es esquemático y estático, y se perciben alineadas cuando son vistas a una distancia de aproximadamente $3 \mathrm{~km}$. No obstante su esquematismo, los geoglifos tienen un gran realismo, ya que se han destacado las patas, hocicos, orejas y colas de los camélidos mediante rocas de menor tamaño dispuestas para resaltar las formas. La presencia de los geoglifos ocurre en la línea de cerros occidentales del valle de San Antonio de los Cobres que separan a las quebradas de Urcuro y Matancillas, en dos lugares diferentes de la entrada a Matancillas.

El primer conjunto, MG1, se encuentra en el faldeo de un gran cerro paralelo al río San Antonio de los Cobres. Es decir, que las representaciones son visibles desde el fondo de cuenca del valle, contiguo a Matancillas, y no lo son desde el interior de las quebradas. El conjunto está compuesto por dos representaciones y es el mejor conservado (Figura 5). El segundo conjunto, MG2, se localiza en la entrada de la quebrada de Matancillas, y también se compone de dos representaciones. Este conjunto está muy deteriorado, reconociéndose las figuras desde una distancia de aproximadamente $500 \mathrm{~m}$, siendo únicamente visible desde el interior de la quebrada, particularmente cuando se atraviesa un portezuelo que conecta ambos conjuntos (Figura 4). En efecto, la ubicación de MG2 ocurre sobre el faldeo oeste de 


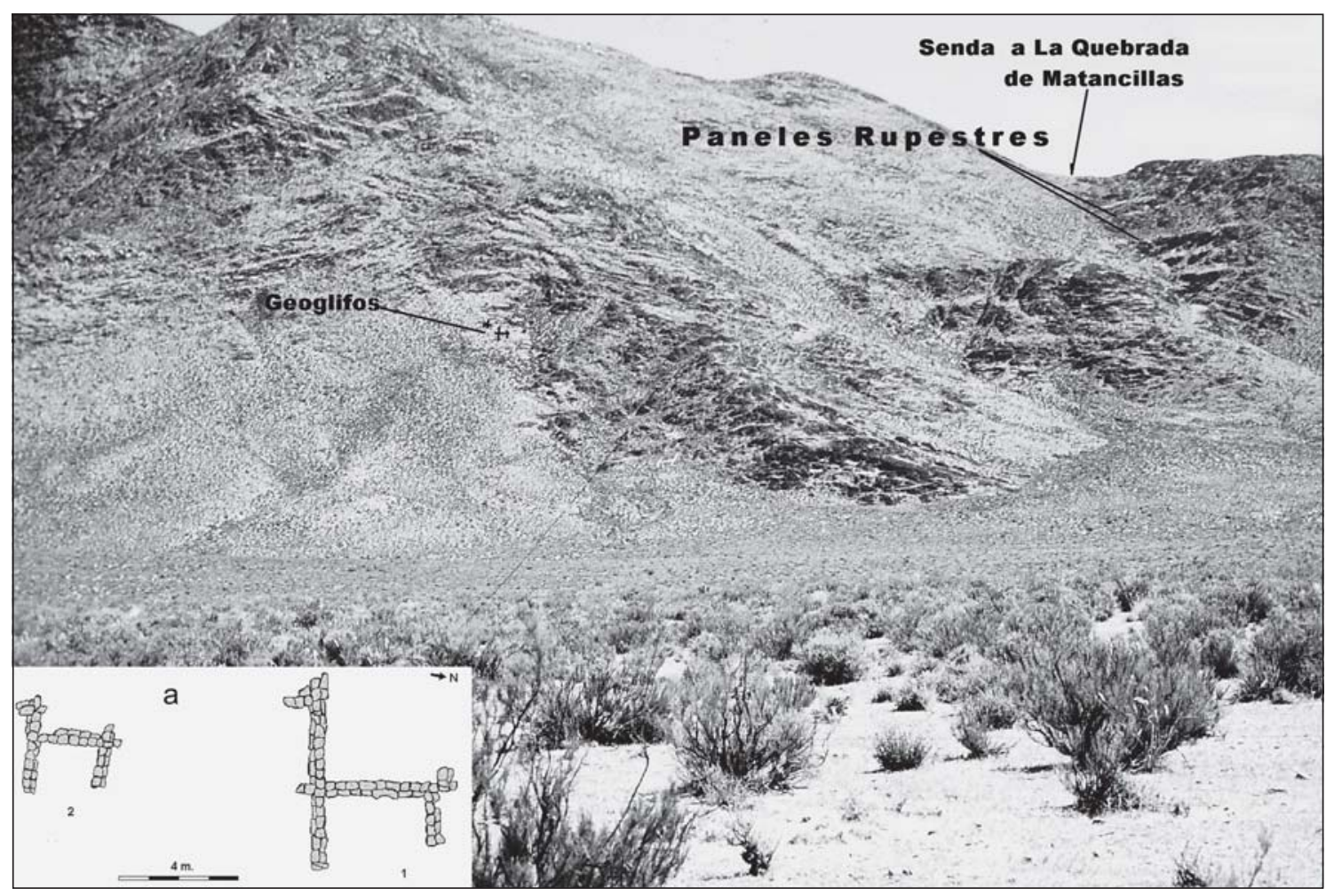

Figura 4. Localización de los geoglifos en la quebrada de Matancillas: a) Detalle de las figuras.

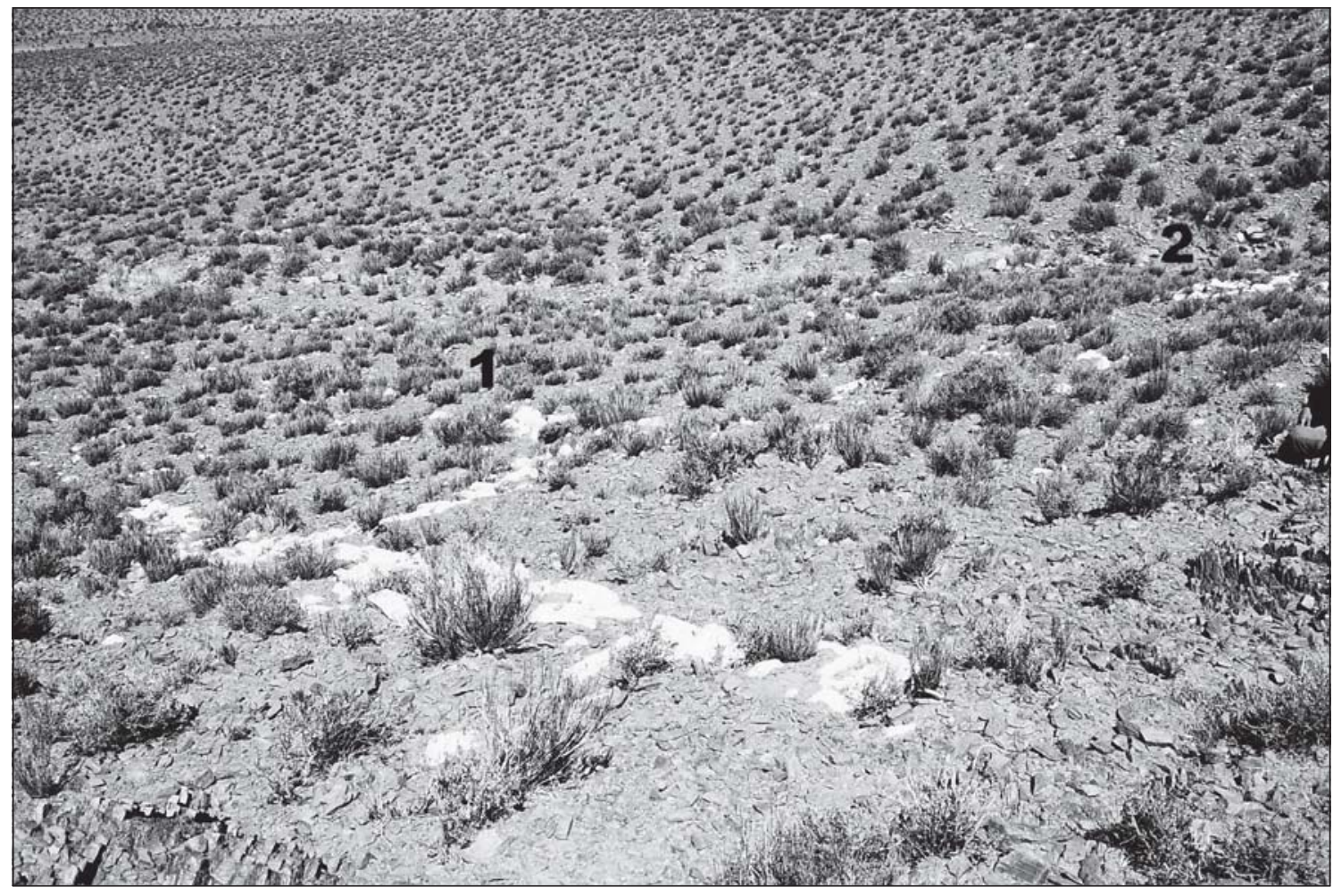

Figura 5. Fotografía de los geoglifos de Matancillas, conjunto MG1. 
un pequeño cerro lateral al valle de San Antonio de los Cobres, que comunica directamente a la quebrada con el fondo de cuenca. Actualmente esta senda natural es utilizada como un atajo para el movimiento de personas y animales hacia el fondo de cuenca, e implica subir hasta una altura de 4110 m.snm, desde donde se desciende fácilmente hacia el fondo de cuenca.

Todos los puntos destacados de este trayecto están señalizados con representaciones rupestres, que demarcan tramos dentro del recorrido. Los puntos extremos están señalizados por los geoglifos, la depresión entre la línea de cerros que forma el abra, está señalizada por petroglifos -es el caso de MP1- y por una apacheta moderna; los sectores de descenso también están señalizados con petroglifos paralelos a caminos muy estrechos, tal es el caso de MP2.

\section{Comportamiento social y representaciones rupestres}

A partir de la ubicación espacial de las representaciones rupestres, distinguimos dos contextos de replicación y uso de las mismas, que son mutuamente excluyentes. El primero es el contexto doméstico-productivo, que comprende lugares con representaciones rupestres directamente asociadas a estructuras residenciales o productivas, tales como las representaciones rupestres de M1, M2 y M3. El segundo es el contexto de tránsito. Se trata de sectores en el paisaje que sirven para la circulación de corta distancia, en la escala local, y de mayor distancia entre diferentes regiones que vinculan a distintos grupos sociales. Las representaciones rupestres de estos contextos ocurren en espacios alejados de las residencias, como los petroglifos de MP1, MP2, y los geoglifos MG1 y MG2.

Los dos contextos se diferencian por el marco y fundamentalmente la escala en el cual tiene lugar la conducta social que incluyó el uso de representaciones rupestres. La distinción de ambos contextos es metodológica, explícitamente diseñada para discutir las hipótesis de trabajo. Teóricamente estos son distintos contextos selectivos, claves para el estudio de los procesos de selección que actuaron sobre las representaciones, a partir de sesgos derivados del comportamiento social de individuos o grupos. En los contextos domésticoproductivos esperamos que la replicación de mo- tivos rupestres haya seguido sesgos derivados mayormente de la vida cotidiana de los individuos. En los contextos de tránsito esperamos que la replicación de diseños rupestres haya estado fuertemente sesgada por la conducta social, vinculada con la movilidad y el flujo de individuos e información, donde tienen lugar las interacciones y la transmisión cultural en el nivel del grupo. La diferenciación entre estos dos contextos responde a las hipótesis planteadas que postulan escalas de interacción social de distinto orden.

Sobre el total de las representaciones individuales de la quebrada de Matancillas realizamos una clasificación según el diseño de cada una de ellas. La Tabla 1 presenta para los dos contextos de uso y replicación de representaciones rupestres: 1) la frecuencia de cada clase de representación, en los petroglifos de M1, M2 y M3, MP2 y en los geoglifos de MG1 y MG2; 2) el total de representaciones identificadas de cada clase por conjunto; 3) la riqueza de clases de cada conjunto; 4) la frecuencia de representaciones no identificables; 5) la presencia o ausencia de superposiciones de representaciones en el conjunto total, y 6) la presencia o ausencia de escenas en los conjuntos. Como puede verse existe una clara diferencia entre las representaciones rupestres presentes en los dos distintos contextos de uso y replicación de las mismas. En los contextos doméstico-productivos la riqueza de clases es mucho mayor, y son los únicos en los cuales las figuras humanas están representadas, mientras que en los contextos de tránsito predominan las pisadas, humanas y no humanas (Figura 6). Esto prueba que actuaron mecanismos de replicación sesgada de representaciones rupestres que fueron diferentes en cada contexto de uso del espacio. Más aún, permite inferir que las representaciones rupestres sirvieron para señalizar el espacio de interacción social en distintas escalas espaciales, donde las presiones selectivas que favorecieron la replicación de motivos y modalidades de diseño fueron divergentes, lo cual nos habilita para discutir las hipótesis planteadas.

\section{Sociabilidad intergrupal y señalización del espacio mediante representaciones rupestres}

A partir de la localización espacial de los petroglifos y geoglifos, y considerando las clases de representaciones ejecutadas, proponemos que la elaboración cultural llevada a cabo por las 


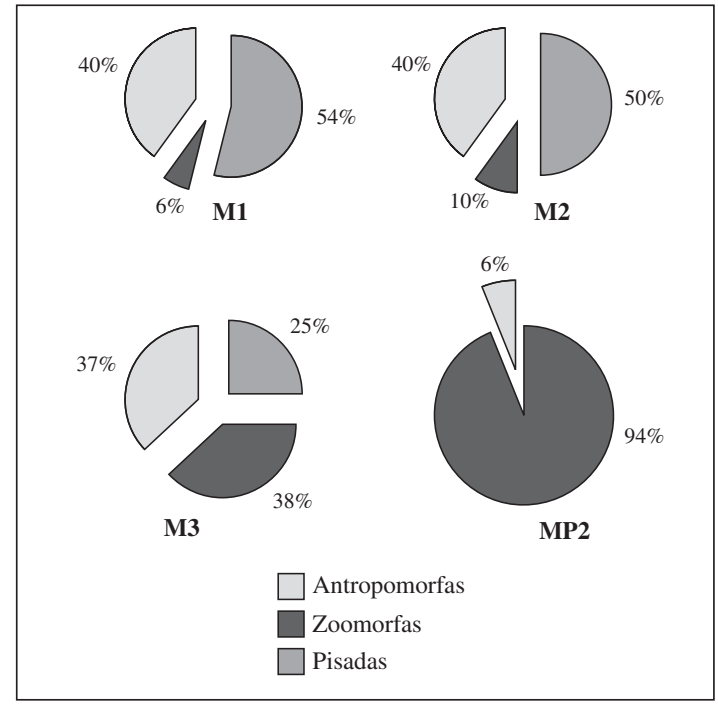

Figura 6. Distribución de las clases de representaciones antropomorfas, zoomorfas y pisadas, en los sitios Matancillas-1, 2 y 3 (M1, M2, M3) y Matancillas Petroglifos-2 (MP2).

representaciones rupestres sirvió para: 1) demarcar territorios de uso exclusivo por grupos locales, y 2) para la señalización de circuitos de movilidad local y de circuitos de movilidad que conectaron distintas sociedades en la mesoescala.

Con relación al uso de las representaciones rupestres en la señalización de territorios, es importante la evidencia de los contextos domésticos y productivos. En ellos encontramos representaciones antropomorfas de uno o más personajes en actitudes estáticas presentados frontalmente, de cuerpos alargados, con los miembros superiores e inferiores cortos esbozados, tocados y rostros delineados por el contraste con el fondo que no fue grabado (Figura 7, M1 panel 29, ver también Figura 3a). Estos diseños son similares a las representaciones alargadas pintadas, características del Período Temprano y relacionadas con la representación de los ancestros. Para estos diseños se ha planteado la relación entre la litomorfización del ancestro en monolitos con la fertilidad de los campos y la demarcación de territorios; es decir, la representación rupestre de las piedras cadáveres (González 1977; Aschero 2000). Siguiendo esta interpretación proponemos que en M1 y M3 estos diseños sirvieron para demarcar territorios exclusivos, mediante la representación rupestre de ancestros. Precisamente esta es una expectativa de la hipótesis de competencia territorial intergrupal.
Además, la representación de ancestros en los contextos doméstico-productivos es una evidencia que favorece a la hipótesis de jerarquías basadas en linajes, la cual se desprende de la lógica de la selección de parentesco (Maschner y Paton 1995).

La señalización de espacios es también evidente por las maquetas, ubicadas en contextos de producción, que pueden interpretarse como representaciones de los espacios explotados y de uso exclusivo por grupos locales (Figura 7, panel 27). Estos diseños aparecen asociados a representaciones de suris y camélidos (Figura 7, paneles 7, 14 y 34). Respecto de la función de las representaciones en la señalización de circuitos de movilidad, los petroglifos localizados en los contextos de tránsito, que comprenden representaciones con motivos de pisadas humanas, círculos, y pisadas de camélidos (Figura 7, MP2 y M3 panel 42) sugieren que sirvieron para señalizar el espacio de movilidad local e intergrupal. Estas representaciones se disponen en vías naturales que conectan diferentes zonas de obtención de recursos, y distintos hábitats que albergaron potencialmente a otras poblaciones locales. Tal es el caso de los petroglifos de MP1 y MP2, que se emplazan en caminos que conectan a Matancillas con la quebrada de Urcuro y con el fondo de cuenca. De este modo, proponemos que estas manifestaciones rupestres se vincularon con el circuito de movilidad de escala local, relacionado principalmente con las actividades de predación y pastoreo, y con la interacción con poblaciones vecinas. En cuanto a los geoglifos, proponemos que su función fue señalizar los circuitos de movilidad ligados con el intercambio. En la mesoescala la geografía del valle de San Antonio de los Cobres está organizada por la planicie del fondo de cuenca, la cual constituye un espacio en donde la circulación humana debió organizarse a partir de la dirección de la cuenca del río homónimo y sus principales afluentes. En esta escala la planicie conecta, de norte a sur, al borde oriental de la puna y la cuenca Guayatáyoc-Salinas Grandes con el norte del valle Calchaquí, y las quebradas de prepuna, como la quebrada del Toro. Hacia el oeste, siguiendo la cuenca del río Tocomar, el valle de San Antonio de los Cobres conecta con las tierras altas orientales de la Puna, y a mayor distancia con el norte de Chile. Etnográficamente existen datos sobre el uso de estas vías de tránsito interregional, en el intercambio de productos ya 


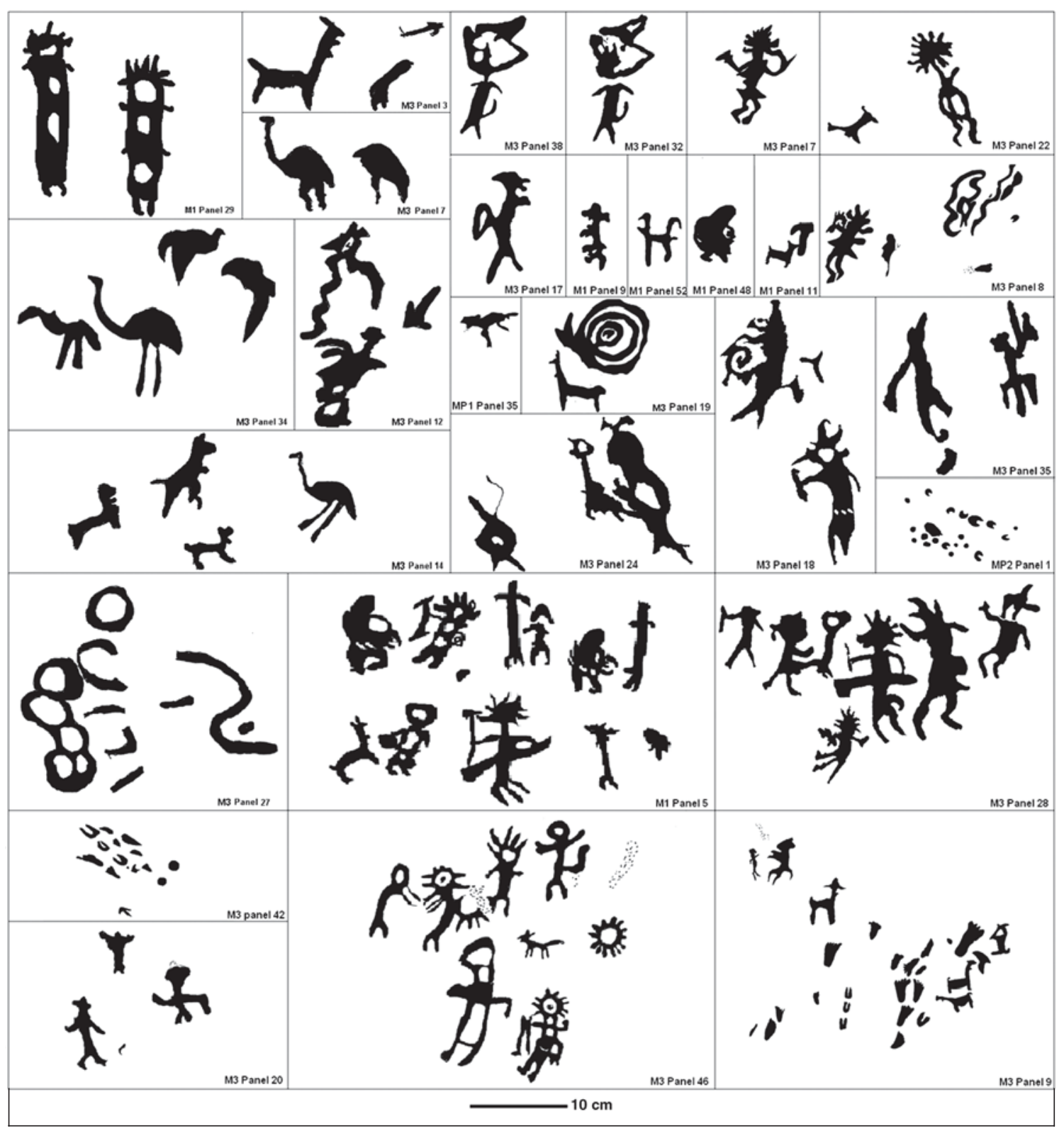

Figura 7. Ejemplos de representaciones por paneles de cada sitio.

sea desde la alta puna a los valles mesotermales o viceversa. Así, en la mesoescala es esperable que la señalización del espacio mediante representaciones rupestres ocurra en el fondo de cuenca. Precisamente esto es lo que muestran los geoglifos del valle.

Tomando el modelo de Aschero (2000), la ocupación de la quebrada de Matancillas se ubica en el lapso "a", en una situación en la cual el tráfico caravanero abarcó grandes distancias, y donde la diversidad iconográfica en el ámbito circumpuneño fue mayor. Así, podemos proponer que una de las derivaciones de este modelo es que los diseños rupestres fueron funcionales para señalizar rutas de intercambio de mesoescala, organizando espacialmente a los circuitos de circulación de bienes, en línea con lo propuesto por otros autores (Aschero 2000; Núñez 1983). Como vimos, los geoglifos constituyen diseños para ser vistos desde distancias largas, cercanas a los $3 \mathrm{~km}$. La localización de MG2 sugiere que fueron concebi- 
dos para señalizar un punto del espacio en el recorrido de la cuenca que desemboca en las Salinas Grandes, la que conecta al resto de las quebradas laterales que presentan evidencias de ocupación humana durante el Temprano, como las del río las Burras y Cobres (Fernández Distel 1998; Muscio 2004). Por esto, puede plantearse que el beneficio obtenido por participar en redes de intercambio de gran escala debió justificar los costos de producción de los geoglifos. Es decir, que esta producción cultural expresa también el beneficio del intercambio y de las interacciones sociales de larga distancia.

Por otra parte, la localización de los geoglifos de MG1, en la entrada a la quebrada de Matancillas sugiere que su construcción fue llevada a cabo para señalizar lugares en los cuales se realizó el intercambio. Notoriamente la tecnología de Matancillas fue muy dependiente de obsidianas provenientes del Cerro Zapaleri, cuya obtención debió provenir del acceso indirecto o intercambio. Sobre la base de esta evidencia proponemos que la construcción de geoglifos fue llevada a cabo con el fin de señalizar espacios de tránsito caravanero y lugares específicos con poblaciones intervinientes en las redes de intercambio. Así señalizados, los faldeos de los cerros se constituyeron en artefactos para la transmisión de información funcional para la interacción intergrupal, relacionada con el flujo de personas y bienes en una estructura social de macroescala.

En suma, sostenemos que las representaciones rupestres de Matancillas emplazadas en contextos de tránsito y movilidad fueron el resultado del comportamiento adaptativo en entornos sociales de alta interacción de grupos. Esta interacción se basó tanto en la competencia como en la cooperación intergrupal establecida por el intercambio, y está en las expectativas de la hipótesis de sociabilidad de mesoescala. Más precisamente, sostenemos que: 1) la representación de ancestros-cadáveres en los espacios domésticos señalizó territorios de uso exclusivo por grupos locales organizados en linajes, en un contexto de competencia intergrupal; es decir, estas representaciones fueron marcas territoriales; 2) los petroglifos emplazados en contextos de movilidad de corta distancia -como Matancillas y Urcuro- donde están ausentes las representaciones humanas sirvieron para señalizar los espacios de tránsito intervinientes en el rango de movilidad de obtención anual de recursos y de interacción con vecinos; 3) los geoglifos sirvieron para señalar los circuitos de movilidad de las actividades de intercambio de mesoescala. A continuación discutimos la elaboración rupestre de Matancillas, relacionada con los procesos de transmisión cultural de la conducta social en el ámbito de lo doméstico.

\section{Sociabilidad intragrupal y arte rupestre}

En la quebrada de Matancillas las representaciones antropomorfas y las escenas que exponen acciones colectivas se restringen únicamente a los contextos doméstico-productivos, en donde el comportamiento social está estrechamente vinculado con la vida cotidiana (Shennan 1988). Desde lo teórico este es el contexto donde tienen lugar los procesos de transmisión cultural intragrupal, horizontal y vertical (sensu Cavalli-Sforza y Feldman 1983). Más precisamente, es el contexto en el cual actúan los mecanismos de aprendizaje cultural de los patrones de comportamiento individual y los sistemas normativos de la conducta (Boyd y Richerson 1985). En los contextos domésticos la evidencia muestra una gran diversidad de diseños de representaciones de figuras antropomorfas y zooantropomorfas. Hay escenas donde ocupan un lugar relevante los personajes con atributos destacados, tales como máscaras, probables tocados, bastones y hachas de mano (Figura 7, panel 8). Las escenas hacen referencia a actividades sociales donde las figuras tienen gran dinamismo, inclusive las que representan interacciones entre personas y camélidos con atributos (Figura 7, panel 46). Estas escenas pueden interpretarse como rituales colectivos (Figura 7, panel 8 y panel 46, con escenificaciones de coito y probablemente danza, y panel 29). En cada una de estas escenas, interpretamos a los personajes con atributos particulares como individuos socialmente diferenciados. Estos aparecen también representados de manera aislada, portando bastones (Figura 7, panel 7), o con piel de felino, en el cual se distingue la cola (Figura 7, panel 22). Este último rasgo es característico del Período Temprano, como también lo son las escenas de actividades sociales con la presencia de individuos con bastones, hachas de mano, máscaras o tocados (Aschero 1996, 2000). Se ha planteado que estos atributos son indicadores de diferencias de estatus o poder, vinculados con las economías productivas (Aschero 1996; Aschero y Korstanje 1995; 
Korstanje y Aschero 1996). Esta interpretación es incompleta, dado que estas representaciones pueden tener por referentes iconográficos a clases de artefactos que funcionan como "emblemas" (Nielsen 2005, 2006) presentes en el bagaje artefactual de la población. Esto es importante, ya que los emblemas marcan posiciones en una estructura social y cuando son corporativos lo hacen en una estructura en la cual las posiciones son apropiadas por grupos, donde los individuos que ocupan esas posiciones lo hacen transitoriamente (Nielsen 2006). Este parece ser el caso de Matancillas. En nuestra opinión, esperamos que conforme aumenta la importancia socialmente significativa de los emblemas estos tiendan a materializarse en artefactos de alto costo, al servicio de la transmisión cultural de información identitaria culturalmente legitimada por sistemas normativos del comportamiento (Shennan 2003). Más generalmente proponemos que la existencia de una alta diversidad de emblemas materializados en artefactos de alto costo manifiesta una estructura social con un aumento en la diferenciación y en la institucionalización de los nichos sociales ocupados por los individuos, y la expresión de poblaciones socialmente heterogéneas.

Aschero (1996) sugiere que en el N.O.A. entre 200-500 DC cobran importancia los tocados como representaciones de estatus, así como las armas y los rasgos felínicos en las figuras de humanos y camélidos, aplicados a máscaras y tocados. Estos atributos están presentes en M1, M2 y M3. Es importante destacar la presencia de personajes con máscaras, tanto en escenas como en representaciones aisladas. Hay dos casos en los cuales la fidelidad de la replicación de los mismos es muy alta (Figura 7, paneles 33 y 32). Se trata de figuras humanas zoomorfizadas, donde se destacan los rabos que pueden ser atribuibles a colas de pieles de felinos utilizadas como capas. Los rostros presentan rasgos felínicos en la nariz y la boca. El personaje central de la escena de danza y coito de M3 tiene estas características. En su cintura presenta lo que puede interpretarse como tamboriles, y en su mano porta un bastón. El personaje también presenta cola atribuible a felino (Figura 7, panel 29). Lo mismo se observa en M1, en una escena donde el personaje central presenta atributos similares (Figura 7, panel 8). En este mismo sitio, se obtuvo la figura modelada de cerámica de un rostro con rasgos de felino, la cual podría ser el referente en la alfarería de esta iconografía

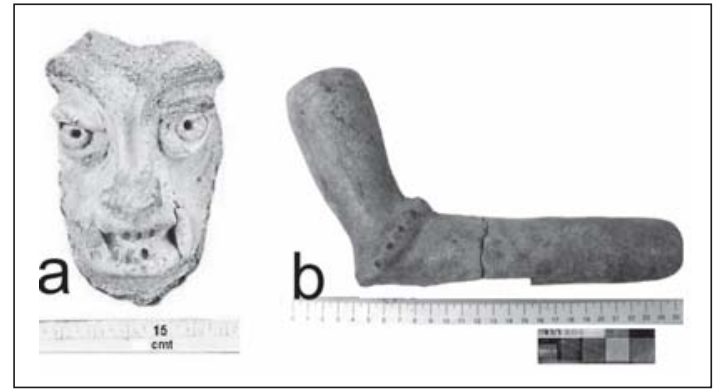

Figura 8. a) Modelado cerámico con la representación de un felino, procedente de Matancillas-1; b) pipa angular procedente de Matancillas-2.

rupestre fechada a comienzos de la era (Figura 8a). Estos personajes con atributos diferenciados a menudo portan tocados que pueden ser interpretados como emplumaduras. Esto es claro en el personaje del extremo inferior de la Figura 7, panel 46, el cual también porta en su mano un bastón doble. Es importante señalar que de contextos excavados se obtuvieron tecnologías de alto costo y uso no utilitario. Es el caso de las pipas, probablemente vinculadas con actividades de alta significación social (Figura 8b). En M1 y M3, tanto la escena como el personaje central presentan una alta fidelidad de replicación, lo cual sugiere la acción de sesgos muy fuertes para la transmisión cultural de estos motivos, especialmente de la información acerca de las acciones representadas en las escenas. Sugerimos que fueron sesgos que favorecieron la transmisión de patrones de comportamiento en rituales colectivos, donde se expresaron fuertemente las jerarquías y los nichos sociales de los individuos.

Como hipótesis interpretativa puede plantearse que estas escenas representan rituales colectivos, donde se expresaron las diferencias sociales, ya que en estas representaciones hay: 1) agregación de individuos en los cuales se destaca su dinamismo; 2) diferenciación de los individuos por los atributos y atuendos que se representaron y por su posición en las escenas; 3 ) representación de personajes centrales demarcados por atributos que remiten a emblemas, tales como bastones, máscaras y tocados, y 4) porque etnográficamente, y a nivel de especie, cada una de estas características definen la conducta ritual colectiva (Chase 1999). En estos términos, el ritual es un conjunto de conductas colectivas e intencionales orientadas a expresar aspectos de la cultura simbólica de un grupo, 
a partir de la dramatización de roles individuales que tienen sentido en una narrativa grupalmente significativa. Si bien los aspectos temáticos de esta narrativa no pueden discutirse con la evidencia disponible, desde la teoría sí es posible inferir algunos elementos funcionales de esta conducta. Ya hemos planteado (Muscio 2004) que el ritual colectivo es un contexto propicio para la competencia interindividual por ocupar nichos de liderazgo en la sociedad, en donde la conducta de organización y ejecución de los mismos constituyen señales costosas (Zahavi 1977), informativas de las habilidades de liderazgo de los individuos en displays con audiencias públicas (Chase 1999). En estos términos, el ritual fue un medio para la transmisión interindividual de los patrones de conducta social, y probablemente para la competencia por nichos sociales de liderazgo. Es decir, constituyeron conductas colectivas en donde tuvo lugar la transmisión cultural de los sistemas normativos del comportamiento interindividual e intergrupal, y la competencia para conseguir o mantener roles institucionalizados de liderazgo (Shennan 2003). En tales performances debieron ser claves las ideas mágicas contraintuitivas, generalizables en cualquier sociedad humana (Boyer 1999). Estas ideas forman parte de sistemas cognitivos que permiten mezclar conceptos de distintos dominios naturalmente separados como, por ejemplo, animales con características humanas y al servicio de la transmisión cultural (Boyer 1999). Sin descartar otras cuestiones vinculadas a los ritos (p.e., rogativas por el pastoralismo, la agricultura o la caza; Aschero 2000); nuestra hipótesis es que en el marco de tales actividades grupales, tuvo lugar la transmisión cultural, que mediante el uso de cultura material sirvió para replicar información atinente a la conducta social, la demarcación de jerarquías y la reproducción del orden social e institucional. Es decir, para la creación de individualidades.

A partir de las representaciones rupestres es posible postular algunas hipótesis acerca de los aspectos más generales del orden social característico de la ocupación temprana de Matancillas. Entre la diversidad de representaciones antropomorfas es importante destacar la presencia de atributos que indican el sexo de los personajes representados, los cuales son siempre masculinos. La demarcación sexual está asociada con elementos del género: la expresión cultural de la diferenciación sexual. Al respecto, las representaciones masculinas -en las que se ha destacado el peneson las únicas que presentan los atributos asociados con desigualdad de poder.

Por otra parte, existen representaciones carentes de rasgos que sugieran sexo, las que en su mayoría son de menor tamaño que las masculinas. Esto es claro en las escenas. Estas representaciones son variadas, pero en ningún caso portan emblemas de jerarquías. Hay una representación aislada en M1 de un personaje de frente con las extremidades ejecutadas frontalmente, con una pierna semiflectada, donde la relación figura fondo demarca la silueta del rostro, y lo que probablemente sea un tocado, y que puede interpretarse como una mujer que porta un cuenco (Figura 3f). Otros casos de representaciones que probablemente remiten a mujeres son aquellos personajes de gran volumen y cuerpo pequeño, con las piernas ausentes o semiflexionadas, y cabezas alargadas, que también parecen portar artefactos utilitarios (Figura $3 \mathrm{~g}$ ). Estas representaciones son diseños de alta fidelidad en su replicación, ya que los hallamos incorporados a escenas o individualmente en M1 (Figura 7 paneles 8 y 48). Sobre la base de esta evidencia arriesgamos la hipótesis de que, en relación al género, en la población de Matancillas lo femenino se vinculó con el ámbito de lo doméstico, en una sociedad ordenada a partir de instituciones masculinas de poder. Reiteramos que las únicas representaciones que denotan sexo son masculinas y que, además, portan emblemas relacionados con posiciones de poder, mientras que los personajes que podrían corresponder a representaciones de mujeres se asocian con tecnologías utilitarias.

Hay consenso en que las sociedades del Temprano estuvieron basadas en unidades familiares de producción, articuladas por relaciones de intercambio (Aschero 2000; Olivera 2001). Este marco fue el propicio para el carácter androcéntrico del orden social de Matancillas. En el mismo, la diversidad de nichos sociales caracterizó a una población socialmente heterogénea, con líderes religiosos y políticos masculinos, sin descartar posibles linajes de identidad grupal basados en mujeres. Esta inferencia es importante, porque implica una sociedad con una diversidad de nichos sociales e instituciones que los legitimaron. La escasez de terrenos productivos y las bajas probabilidades de dispersión habrían propiciado la existencia de jerarquías efectivas para disminuir la competencia 
intragrupal y para administrar las posibilidades de dispersión espacial con el fin de minimizar el riesgo. Así proponemos que la elaboración rupestre de Matancillas expresa esta situación, con líderes masculinos reproduciendo este orden social y sus instituciones. Esto no implica jefaturas ni toma de decisión centralizada, sino simplemente individuos encargados de representar los intereses de su comunidad a cambio de prestigio premiado con fitness (Kelly 1995).

Respecto a la alta diversidad de los diseños, existen muchos que son recurrentes en el arte rupestre del Período Temprano del N.O.A., en particular las representaciones de camélidos con marcas que Aschero (2000) denomina "enflorados", y que, salvo el caso de Matancillas, comprende diseños pintados. Otro caso que manifiesta regularidades de significación temporal, son los motivos que recuerdan a los camélidos cuadricéfalos de Antofagasta de la Sierra (Olivera y Podestá 1993) (Figura 7, panel 52). Pero también existen representaciones particulares de carácter local, como las escenas en las cuales interviene una diversidad de personajes y que aquí hemos interpretado como alusivas a rituales. De tal modo, el caso de Matancillas es interpretable en el momento "a" del modelo de Aschero (2000), cuya principal característica fue una alta diversidad regional en el contexto de redes amplias de tráfico caravanero, donde los contextos de significación respondieron a ideologías basadas en la producción doméstica de familias, conectadas por antepasados. Nosotros coincidimos con esta propuesta y agregamos que estos órdenes sociales basados en familias promueven la retención de una mayor variación cultural en el nivel del grupo, por los efectos de la transmisión conformista (Boyd y Richerson 1996). Una de las características de este mecanismo es que permite la diferenciación cultural de grupos, aun cuando la conectividad entre poblaciones es alta (Henrich y Boyd 1998). Esta era la situación cuando las redes de intercambio fueron muy amplias, conectando a las poblaciones locales circumpuneñas. Por esto, la transmisión conformista debió actuar manteniendo una mayor diversidad interregional de representaciones rupestres, como un producto de la diferenciación de grupos. El análisis filogenético, cladístico, puede resolver esta cuestión (O’Brien y Lyman 2002).

\section{Discusión}

Concibiendo a las representaciones rupestres como una extensión del fenotipo humano concluimos que la señalización visual del espacio en la quebrada de Matancillas fue un proceso de construcción de un entorno cognitivo hereditario. Es decir, los individuos no sólo heredaron información cultural, sino también un entorno modificado. Esto fue un producto selectivo en el cual intervino el comportamiento social interindividual e intergrupal. Así, los elementos del ambiente físico y ciertos lugares discretos del paisaje fueron transformados en artefactos para la transmisión cultural de información de carácter política, constituida en la vida cotidiana y transgeneracionalmente reproducida.

La elaboración cultural de las representaciones rupestres de Matancillas fue el resultado de la institucionalización de un orden social emergente de la competencia, en el cual la complejidad social estuvo basada en jerarquías de carácter hereditario, en la diferenciación de nichos sociales y en instituciones masculinas de poder. Esto tuvo lugar en una sociedad en la cual las unidades domésticas fueron los agentes de producción y organización política. Del proceso de elaboración cultural rupestre resultó la construcción de un entorno cuya dimensión simbólica permitió: 1) la transmisión de información cultural, al servicio de la demarcación de territorios o de puntos en redes de caravaneo, y 2) la evocación en términos emocionales y cognitivos (Shennan 1988), de información con respecto a nichos sociales, conductas domésticas y sistemas normativos del comportamiento interindividual (Chase 1999). Esto tuvo por efecto la formación de individualidades en el marco de un orden social jerarquizado. En consecuencia, la asociación de representaciones rupestres con las redes de caravaneo o con lugares de uso económico fue solamente una de las dimensiones funcionales de este paisaje de significaciones, cuya función principal habría sido de índole política. Particularmente, la transmisión cultural de información sobre el orden social e institucional, del cual participaron los individuos de la población de Matancillas durante el Período Temprano. Como hemos sostenido, una de las características de este orden social fue su carácter androcéntrico, lo que no implica que las mujeres no habrían tenido lugar en la reproducción de este orden social ni que fueran carentes de autonomía. 
Desde lo teórico la transmisión cultural vertical supone un balance entre los padres culturales de ambos sexos de un individuo naïf, de manera simétrica a la transmisión genética (Boyd y Richerson 1985). Es decir, que el rol de las mujeres debió ser tan importante como el de los hombres en la transmisión cultural de la información atinente al orden social, en edades tempranas de la ontogenia de los individuos. Pero si nuestra hipótesis de que los rituales fueron performances para la transmisión cultural es correcta, entonces es la transmisión horizontal lo que cuenta. Bajo este modo de transmisión determinados modelos para imitar, en este caso hombres con poder diferenciado, son los principales individuos intervinientes en los procesos de transmisión cultural. Al proceso de retención de variación cultural por esta vía Durham (1992) lo denominó role selection. Independientemente de si las mujeres tuvieron nichos de privilegio para la transmisión cultural, o aun para la conformación de linajes de identidad colectiva, lo central finalmente es: ¿quienes fueron los individuos culturalmente habilitados para la toma de decisión y la reproducción del orden social, sobre los cuales recaía el poder genuino acerca del funcionamiento de las instituciones sociales? La elaboración rupestre de Matancillas sugiere que estos eran hombres, y que ocuparon nichos sociales con el potencial efectivo para constituirse en modelos para imitar y para generar la persistencia de un orden androcéntrico por procesos de role selection. La biología evolutiva humana, basada en el dimorfismo sexual de las estrategias reproductivas entre sexos, apoya esta idea (Chase 1999).

Más precisamente, la evidencia global de Matancillas se ajusta al modelo de Harpending y Cochran (2002), según el cual las sociedades agrícolas con baja escala de productividad y en bajas densidades poblacionales propician entornos adaptativos adecuados para la expresión de los condicionantes genéticos del comportamiento competitivo masculino: el alelo $7 \mathrm{R}$ asociado al fenotipo ADHD. Según esto, en tales sociedades el esfuerzo reproductivo de los hombres se invierte principalmente en la búsqueda de parejas reproductivas, mientras que las mujeres absorben los costos parentales y gran parte del trabajo en los cultivos. Precisamente esta hipótesis predice un peso mayor de las mujeres en la transmisión cultural a los individuos jóvenes, y el rol de los hombres en la transmisión horizontal de patrones de comportamiento orientados a la competencia masculina, lo que da lugar a la competencia interindividual masculina y a la evolución de sociedades androcéntricas. Este patrón de absorción del costo parental por las mujeres ha sido observado en sociedades etnográficas de la Puna de Salta (Azcune y Gómez 2002 Ms).

El caso de Matancillas se ajusta a las expectativas de la genética del comportamiento propuesta por Harpending y Cochran (2002). Además, los tamaños poblacionales pequeños y la baja escala de producción habrían sido característicos del Período Temprano (Olivera 2001), por lo cual los órdenes sociales androcéntricos y con niveles altos de competencia intragrupal, pudieron haber caracterizado a gran parte de las poblaciones de dicho período, que incluyeron a la agricultura en su nicho económico. Esta hipótesis imparte una línea de investigación futura, basada en el estudio arqueológico de las dispersiones démicas de macroescala, ya que el fenotipo ADHD y su expresión alélica es muy frecuente en las poblaciones de las tierras bajas sudamericanas. El conocimiento de la historia cultural de la Puna argentina desde los comienzos de su ocupación indica una alta conectividad demográfica con poblaciones de las tierras bajas subandinas, por lo cual el flujo genético es lo esperable y del cual existe alguna evidencia (Cocilovo et al. 2001).

En síntesis, en el ámbito doméstico la producción rupestre en Matancillas durante el período que tratamos sirvió básicamente para la reproducción del orden social. En el marco del mismo se constituyeron individualidades androcéntricas (Shennan 2002). Por la perduración transgeneracional de esta producción cultural, los espacios con representaciones rupestres se constituyeron en artefactos para la transmisión cultural de la ideología del grupo, para su evocación y para el aprendizaje transgeneracional de las pautas de comportamiento social de hombres y mujeres, institucionalizando la cooperación intergrupal, las interacciones de intercambio y la desigualdad social. Esto último es evidente en las representaciones de ancestros-cadáveres que sugieren desigualdad por linajes, aun cuando estas representen mujeres ancestros. Precisamente no es casual que el ámbito doméstico haya sido el principal contexto selectivo de información cultural, por mecanismos de transmisión sesgada, del cual expusimos ejemplos. 
Por otra parte, las representaciones rupestres en Matancillas exponen una alta diversidad de motivos, entre los cuales tienen alta frecuencia las representaciones de tecnologías vinculadas con la sociabilidad y el estatus. Esto indica una alta inversión global en tecnología, siendo lo esperable para poblaciones de baja movilidad y con estrategias de producción de alimentos, donde los costos de las tecnologías disminuyen, particularmente de las que intervienen en la sociabilidad y en la competencia interindividual (Kelly 1995).

En la escala circumpuneña la evidencia no sólo muestra la señalización del espacio, sino también la existencia de individuos con roles sociales ligados con el intercambio. Esto tiene sentido considerando la evidencia de poblaciones que ocuparon ambientes locales con nichos económicos divergentes. Es el caso de Susques, donde el nicho económico fue de pastoreo y caza durante todo el Período Temprano (Yacobaccio et al. 1998). Esta es la precondición para el mutualismo económico (Boone 1992; Layton 2001) minimizador de riesgos, y se explica por el modelo de tráfico con movilidad giratoria circumpuneño (Núñez y Dillehay 1978). Reconociendo la variabilidad ecológica de la Subárea Circumpuneña es esperable una alta diversidad de órdenes sociales locales, vinculados con el nicho económico local. Por ejemplo, en los sistemas organizativos y en la escala de complejidad entre ocupaciones con un predominio de la agricultura y aquellas en las cuales predominó el pastoralismo, como en Susques. Sin embargo, debieron haber sido comunes las instituciones que garantizaron el intercambio interregional en un orden social inclusivo y basado en el tráfico de recursos. El caso de Tulan-54 parece señalar la emergencia del mismo en los Andes surandinos (Núñez 1994).

En Matancillas la estrategia tecnológica fue dependiente de recursos líticos no locales. En consecuencia, debió basarse en un sistema de distribución que aseguró la alta disponibilidad de estos recursos. Las estrategias tecnológicas altamente dependientes del intercambio requieren de la existencia no sólo de potenciales agentes de intercambio, sino fundamentalmente de la persistencia de órdenes sociales capaces de minimizar las fluctuaciones y la incertidumbre de las condiciones de intercambio y del abastecimiento de los recursos en juego. Esto demanda individuos que garantizan los contratos sociales y económicos, es- tableciendo certeza acerca de las acciones recíprocas. Así, sugerimos que la población de Matancillas participó de una sociedad de mayor escala, donde el aprovisionamiento de los recursos líticos de alta calidad fue poco fluctuante, por la existencia de agentes que garantizaron la circulación de bienes y los acuerdos de intercambio. Este fue el rol de los caravaneros y de su nicho social. En estos términos puede explicarse la perduración de largo plazo de redes de circulación de obsidiana, que se interrumpen con la expansión incaica (Yacobaccio et al. 2002). Estas fueron posibles por la persistencia de instituciones que garantizaron contratos sociales efectivos para el intercambio entre distintas poblaciones locales, incluyendo la de la quebrada de Matancillas. Es decir, economías abiertas tendientes a la previsibilidad. Este planteo no implica especializaciones con respecto al nicho social de los caravaneros. Estos muy probablemente fueron los mismos jefes de las unidades domésticas. Esta situación es la esperable en economías de baja escala, y ha sido observada etnográficamente (Nielsen 1998; Muscio 2004). En estos casos las restricciones de inversión temporal no son limitativas para la ocupación de más de un nicho social por parte de los individuos. Lo importante es que estos individuos ampliaron la diversificación de nichos sociales y la escala de la complejidad social.

Este trabajo es interpretativo, dado que brinda hipótesis de los referentes de las representaciones rupestres, pero no de sus contenidos simbólicos. Respecto de las hipótesis, estas quedan abiertas para su contrastación con evidencia independiente. La evidencia paleodemográfica es una de las principales líneas de investigación a seguir para responder aspectos del orden social de poblaciones arqueológicas (Shennan 2003).

El estudio de la dimensión social de las poblaciones tempranas con economías de producción de alimentos en el N.O.A. se suele abordar en el marco de nociones progresivistas del cambio a partir de la noción de Formativo. Esta constituye una unidad de análisis con contenido teórico, que no sólo describe a la variabilidad, sino a sus causas que se plantean en el marco de la tendencia inherente de las sociedades humanas al progreso económico e institucional, dentro del paradigma evolutivo progresivista spenceriano (Muscio 2001). En estos términos, salvo excepciones (Aschero y Korstanje 1995; Korstanje y Aschero 
1996; Nielsen 1995, entre otros), se describen a las sociedades agroganaderas tempranas del N.O.A. como sociedades tribales, constituidas por una serie gradualmente inclusiva de grupos basados en familias, mayormente igualitarias y tendientes a la autosuficiencia económica, asumiendo relaciones de cooperación beneficiosas en el nivel del grupo (Raffino 1988; Tarragó 1999). Esta imagen es una analogía etnográfica directa de las llamadas "economías tribales Zen" (Sahlins 1972), e implícitamente asume adaptación en la escala del grupo (Maschner y Paton 1995; Kelly 1992). Además, es una propuesta que suprime la variabilidad que puede manifestar el registro arqueológico del comportamiento social (Nielsen 1995). Al respecto, la evidencia de Matancillas sugiere que la imagen de sociedades igualitarias y tendientes a la autosuficiencia económica no es adecuada; como tampoco lo es aquella que ignora el conflicto derivado de la competencia. Desde la perspectiva materialista evolutiva aquí adoptada, la imagen que nos brinda el análisis de la elaboración rupestre de Matancillas y del conjunto de la evidencia arqueológica es la de una sociedad políticamente desigual, por estatus y por género, no basada en la autosuficiencia y con instituciones derivadas del conflicto selectivo.

Finalmente, termino este trabajo refiriéndome a una cuestión central para su correcta interpretación. Explicar y justificar la conducta son cosas diferen- tes. Quienes suponen que los acercamientos biológicamente inspirados al comportamiento humano implican que lo "natural" es lo moralmente deseable, caen en el error lógico de confundir las afirmaciones acerca de lo que "es" con las afirmaciones de lo que "debería ser". Las últimas no se derivan de las primeras. Por supuesto, esto es válido también para las conductas culturalmente explicadas, que muchas veces no son tolerables ni deseables en los acuerdos éticos de nuestra propia cultura. Por esta razón, la conclusión más aguda de este trabajo acerca de la existencia de un orden social androcéntrico pasado, sostenible desde nuestro conocimiento aún rudimentario de la genética del comportamiento humano y de la evidencia arqueológica, no debe confundirse con una justificación moral del mismo. Entonces el mensaje es muy claro: si ni la biología ni la cultura son destino, los órdenes sociales no son inmutables. Esta idea corrosiva es el legado persistente de Darwin.

Agradecimientos Este trabajo se realizó con financiamiento del CONICET. Agradezco profundamente a Celia Mercuri y a Sebastián Frete por su ayuda en el campo, y a Axel Nielsen por la discusión de ideas clave que enriquecieron notablemente este trabajo. También agradezco a los revisores, ya que sus aportes fueron clave para mejorar el contenido del trabajo. Finalmente, mi agradecimiento permanente a Stephen Patrick Morrisey por su inspiración.

\section{REFERENCIAS CITADAS}

ASCHERO, C., 1996. Arte y arqueología: Una visión desde la Puna argentina. Chungara 28 (1 y 2): 175-197.

2000. Figuras humanas, camélidos y espacios en la interacción circumpuneña. En Arte en las rocas. Arte rupestre, menhires y piedras de colores en Argentina, M. Podestá y M. de Hoyos (Eds.), pp. 17-44. Editorial Sociedad Argentina de Antropología, Buenos Aires.

ASCHERO, C. y A. KORSTANJE, 1995. Sobre figuras humanas, producción y símbolos. Aspectos del arte rupestre del Noroeste Argentino. En XXV Aniversario del Museo Arqueológico Dr. Eduardo Casanova, pp. 65-89. Instituto Interdisciplinario de Tilcara, Universidad de Buenos Aires, Tilcara.

AZCUNE, C. y M. GOMEZ, 2002 Ms. Discutiendo escalas en arqueología y evolución. Ponencia presentada en el XIV Congreso de Arqueología Argentina. Rosario.
BOONE, J. L., 1992. Competition, conflict and development of social hierarchies. En Evolutionary ecology and human behavior, E.A. Smith y B. Winterhalder (Eds.), pp. 301337. Aldine de Gruyter, Nueva York.

BOYD, R. y P. J. RICHERSON, 1985. Culture and the evolutionary process. University of Chicago Press, Chicago.

1996. Why culture is common, but cultural evolution is rare. Proceedings of the British Academy 88: 73-93.

BOYER, P., 1999. Cognitive tracks of cultural inheritance: How evolved intuitive ontology governs cultural transmission. American Anthropologist 100 (4): 876-889.

CAVALLI-SFORZA, L. L. y M. FELDMAN, 1983. Cultural transmission and evolution: A quantitative approach. Princeton University Press, Princeton. 
COCILOVO, J., H. VARELA y S. VALDANO, 2001. Estructura de la población antigua de la quebrada de Humahuaca. En Historia argentina prehispánica, E. Berberián y A. Nielsen (Eds.), T 1, pp. 265-287. Editorial Brujas, Córdoba.

CHAGNON, N., 2000. Manipulating kingship rules. A form of male yanomamo reproductive competition. En Adaptation and human behavior an anthropological perspective, L. Cronk, N. Chagnon y W. Irons (Eds.), pp. 115-147. Aldine de Gruyter, Nueva York.

CHASE, P. G., 1999. Symbolism as reference and symbolism as culture. En The evolution of culture, R Dumbar, C. Knight y C. Power (Eds.), pp. 34-49. Rutgers University Press, Nueva Jersey.

DAWKINS, R., 1976. The selfish gene. Oxford University Press, Oxford.

-1982. The extended phenotype: The gene as the unit of selection. W. H. Freeman \& Company, Nueva York.

DENNETT, D. C., 1995. Darwin's dangerous idea: Evolution and the meanings of life. Touchstone Editions, Nueva York.

DICKENS, P., 2000. Social darwinism, linking evolutionary though to social theory. Open University Press, Philadelphia.

DUMBAR, R., 1999. Culture, honesty and the freerider problem. En The evolution of culture, R Dumbar, C. Knight y C. Power, (Eds.), pp. 194-213. Rutgers University Press, Nueva Jersey.

DURHAM, W. H., 1992. Coevolution: Genes, culture and human diversity. Stanford University Press, Stanford.

FERNANDEZ DISTEL, A., 1998. Arqueología del Formativo en la Puna jujeña 1800 AC- 650 DC. Editorial Dunken, Buenos Aires.

FOLEY, R. A., 1995. Causes and consequences in human evolution. Journal of the Royal Anthropological Institute 1: $67-86$.

GONZALEZ, A. R., 1977. Arte precolombino en Argentina. Editorial Valero, Buenos Aires.

GINTIS, H., 2000. Game theory evolving. Princeton University Press, Princeton.

HAMILTON, W. D., 1964. The genetical evolution of social behavior. Journal of Theoretical Biology 7: 1-16.

HARPENDING, H. y G. COCHRAN, 2002. In our genes. Proceedings of the National Academy of Science 99: 10-12.

HENRICH, J. y R. BOYD, 1998. The evolution of conformist transmission and the emergence of between-group differences. Evolution and human behavior 19: 215-231.
KELLY, R. L., 1992. Mobility/sedentism: Concepts, archaeological measures, and effects. Annual Review of Anthropology 21: 43 -66.

-1995. The foraging spectrum diversity in hunter-gatherer lifeways. Smithsonian Institution Press, Washington D. C.

KOSSE, K., 1994. The evolution of large, complex groups: A hypothesis. Journal of Anthropological Archaeology 13: $35-49$.

KORSTANJE, A. y C. ASCHERO, 1996. Arte rupestre en los valles de El Bolsón y Las Cuevas (Catamarca, Argentina): Formulando hipótesis de cambio y conflicto. Chungara 28: 199-122.

KREBS, J. R. y N. B. DAVIS, 1991. Behavioral ecology: An evolutionary approach. Blackwell Scientific, Oxford.

LAYTON, R. H., 2001. Hunter-gatherers, their neighbours and the Nation state. En Hunter-gatherers an interdisciplinary perspective, C. Panter Brick, R. Layton y P. Rowley Conwy (Eds.), pp. 292-321. Cambridge University Press, Cambridge.

MASCHNER, H. D. y J. Q. PATTON, 1995. Kin selection and the origins of hereditary social inequality: A case study from the Northern Northwest Coast. En Darwinian archaeologies, H. G. Maschner (Eds.), pp. 89-107. Plenun Press, Nueva York.

MAYNARD SMITH, J., 1964. Group selection and kin selection. Nature 201: 1145.

-1974. The theory of games and the evolution of animals conflicts. Journal of Theoretical Biology 47 (1): 209-221.

MUÑOZ, I. y L. BRIONES, 1998. Poblados, rutas y arte rupestre precolombinos de Arica: Descripción y análisis de sistemas de organización. Chungara 28: 47-84

MUSCIO, H., 1998. Patrones espacio-temporales de la variabilidad ambiental en la Puna argentina: Algunas implicancias para la ecología humana prehistórica del N.O.A. y para la estructura arqueológica regional. Cuadernos del INAPL 18: 271-296.

2001. Una revisión crítica del Arcaico surandino. Editorial Opfyl, Universidad de Buenos Aires, Buenos Aires.

2002. Cultura material y evolución. En Perspectivas integradoras en arqueología y evolución: Teoría, métodos y casos de aplicación, G. A. Martínez y J. L. Lanata (Eds.), pp. 21-54. Investigaciones Arqueológicas y Paleontológicas del Cuaternario (INCUAPA), Universidad Nacional del Centro de la Provincia de Buenos Aires, Olavarría.

2004. Dinámica poblacional y evolución durante el Período Agroalfarero Temprano en el Valle de San Antonio de los Cobres, Puna de Salta, Argentina. Tesis Doctoral, Facultad de Filosofía y Letras, Universidad de Buenos Aires, Buenos Aires. 
NIELSEN, A., 1995. El pensamiento tipológico como obstáculo para la arqueología de los procesos de sociedades sin Estado. Comechingonia 8: 21-46.

-1998. Tráfico de caravanas en el sur de Bolivia: Observaciones etnográficas e implicancias arqueológicas. Relaciones XXII-XXIII: 139-178.

-2005. Prácticas corporativas y tráfico interregional en los Andes circumpuneños. En Libro de resúmenes del Taller Procesos Sociales Prehispánicos en los Andes Meridionales, A. Nielsen (Ed.), pp. 36-37. Instituto Interdisciplinario Tilcara, Universidad de Buenos Aires, Tilcara.

2006. Celebrando con los antepasados: Arqueología del espacio público en Los Amarillos, Quebrada de Humahuaca, Jujuy, Argentina. Mallku Ediciones, Buenos Aires.

NUÑEZ, L., 1976. Geoglifos y tráfico de caravanas en el desierto chileno. Homenaje al Dr. Gustavo Le Paige, pp. 147-201. Universidad del Norte, Antofagasta.

1983. Petroglifos y tráfico en el desierto chileno. En Estudios de arte rupestre, C. Aldunate, J. Berenguer y V. Castro (Eds.), pp. 243-264. Museo Chileno de Arte Precolombino, Santiago.

1994. Emergencia de complejidad social y arquitectura jerarquizada: Las evidencias del sitio Tulan-54. En De costa a selva: Producción e intercambio entre los pueblos alfareros de los Andes Centro Sur, M. E. Albeck (Ed.), pp. 85-116. Instituto Interdisciplinario de Tilcara, Universidad de Buenos Aires, Tilcara.

NUÑEZ, L. y T. DILLEHAY, 1978. Movilidad giratoria, armonía social, y desarrollo en los Andes Meridionales: Patrones de tráfico e interacción económica. Universidad del Norte, Antofagasta.

O'BRIEN, M. J. y R. LYMAN, 2002. Evolutionary archaeology: Current status and future prospects. Evolutionary Anthropology 11: 26-36.

OLIVERA, D., 2001. Sociedades agropastoriles tempranas: El Formativo Inferior del Noroeste Argentino. En Historia argentina prehispánica, E. Berberián y A. Nielsen (Eds.), T 1, pp. 83-125. Editorial Brujas, Córdoba.

OLIVERA, D. y M. PODESTA, 1993. Los recursos del arte: Arte rupestre y sistemas de asentamiento-subsistencia formativos en la Puna Meridional argentina. Arqueología 3: $93-141$.

PIANKA, E. R., 1995. Ecología evolutiva. Editorial Omega, Barcelona.

RAFFINO, R., 1988. Poblaciones indígenas en Argentina. Editorial TEA, Buenos Aires.

SAHLINS, M., 1972. Stone age economics. Aldine de Gruyter, Chicago.

SHENNAN, S., 1988. Cultural transmission and cultural change. En What's new? A Closer look at the process of innovation, S. van der Leeuw y R. Torrence (Eds.), pp. 330-346. Unwin Hyman, Nueva York.

2002. The Darwinian archaeology of social norms and institutions. Issues and examples. En Perspectivas integradoras en arqueología y evolución: Teoría, métodos y casos de aplicación, G. A. Martínez y J. L. Lanata (Eds.), pp. 157-174. Investigaciones Arqueológicas y Paleontológicas del Cuaternario (INCUAPA), Universidad Nacional del Centro de la Provincia de Buenos Aires, Olavarría.

2003. Genes, memes and human history: Darwinian archaeology and cultural evolution. Thames and Hudson, Londres.

SMITH, E. A. y B. WINTERHALDER, 1992. Natural selection and decision-making: Some fundamental principles. En Evolutionary ecology and human behavior, E. A. Smith y B. Winterhalder (Eds.), pp. 25- 60. Aldine de Gruyter, Nueva York.

SUGIYAMA, L. y R. CHACON, 2000. Effects of illness and injury on foraging among the Yora and Shiwiar pathology risk as adaptive problem. En Adaptation and human behavior an anthropological perspective, L. Cronk, N. Chagnon y W. Irons (Eds.), pp. 371-412. Aldine de Gruyter, Nueva York.

TAINTER, J. A., 1995. Prehistoric societies as evolving complex systems. En Evolving complexity and environmental risk in prehistoric southwest, J. Tainter y B. B. Tainter (Eds.), pp. 1-24. SFI \& Addison-Wesley Logman, Washington D. C.

TARRAGO, M., 1992. El Formativo y el surgimiento de la complejidad social en el Noroeste Argentino. En Formativo sudamericano. Una reevaluación. Homenaje a A. $R$. González y B. J. Meggers, P. Ledergerber-Crespo (Ed.), pp. 302-313. Abya-Yala, Quito.

TOOBY, J. y L. COSMIDES, 1992. The psychological foundation of culture. En The adapted mind: Evolutionary psicology and the evolution of culture, J. H. Barkow. L.Cosmides y J. Tooby (Eds.), pp.19-36. Oxford University Press, Oxford.

TRIVERS, R., 1971. The evolution of reciprocal altruism. Quarterly Review of Biology 46: 35-42.

WILSON, E., 1975. Sociobiology: The new synthesis. The Harvard University Press, Cambridge.

WINTERHALDER, B., 2001. Intragroup resource transfers. Comparative evidence, models and implications for human evolution. En Meat eating and human evolution, C. B. Stanford y H. T. Bunn (Eds.), pp. 279-291. Oxford University Press, Oxford.

WINTERHALDER, B. y C. GOLAND, 1997. An evolutionary ecology perspective on diet choice, risk, and plant domestication. En People, plants, and landscapes. Studies in paleoethnobotany, K J. Gremillion (Ed.), pp. 123-160. University of Alabama Press, Alabama. 
YACOBACCIO, H., 1979. Arte rupestre y tráfico de caravanas en la Puna de Jujuy. Modelo e hipótesis. Antiquitas Revista de la Universidad del Salvador 2: 12-21.

YACOBACCIO, H., C. MADERO, M. MALMIERCA y M. REIGADAS, 1998. Caza, domesticación y pastoreo de camélidos en la puna argentina. Relaciones XXII-XXIII: 389-421.
YACOBACCIO, H., P. ESCOLA, M. LAZZARI y F. PEREYRA, 2002. Long-distance obsidian traffic in Northwestern Argentina. En Geochemical evidence for long-distance exchange, M. Glascock (Ed.), pp. 167-203. Bergin and Garvey, Westport, Connecticut.

ZAHAVI, A., 1977. Reliability in communication systems and the evolution of altruism. En Evolutionary ecology, B. Stonehouse y C. M. Perrins (Eds.), pp. 253-267. Macmillan, Londres. 